\title{
Effects of Restorative
}

\section{Environments on Creativity in Case of Architecture \\ Education}

BESTE SABIR

Istanbul Technical University 
Creativity is a mental process, as Andreasen (2006) describes, it happens when a thought comes up to surface in the mind, it has a complex nature and it does not happen in a tabula rasa condition, instead interaction of human thoughts with socio-cultural situations creates this phenomenon, as Portillo (1996) defines the creativity as an interconnected and multidimensional construct involving person, process, product and place (environment/ press). One of the main intentions of this paper is to address the relationship between the creativity and its supportive environment in case of architectural education which can be defined as a design study that get its origins from creativity.

Freeman (1971) categorizes creativity with the stages such as: Preparation; Incubation; Enlightenment (A-ha moment, enlightenment); Affirmation/Verification. Following that organization, we can consider that first two stages are very complex, intricate and interactive processes and in case of architectural education and its environmental necessities, designs should be answering to this complexity and interactivity as well.

It is important to consider creativity as the major source in any kind of thinking, and as inseparable from life itself (DeBono, 1993). Any understanding of education and learning includes the term creativity, and thus, the learning environment should carry the necessary components to support it (Demirbas \& Demirkan, 2000; Hasirci, 2000). The learning environment in which learning and creative activities take place, should provide students the ground on which creativity can more readily flourish (Hasirci, 2000). There are also arguments whether creativity is latent potentiality or an improvable characteristic (Potur, Barkul, 2006). For the first time in Utah Research Conference in 1959, researchers argued about creativity and its relationship with education, and if it can be developed. (Andreasen, 2006) As Guilford (1950) describes, like many other activities, creativity is a behavior that can be developed and learned. This paper focuses on to the neuroscience of creativity and its supportive environments that can develop this ability in architectural education.

Andreasen (2006) supports Freeman's creativity categorization; and deepens the A-ha moment stage: Eventhough creativity is a complex process, while the brain is in the REST mode - which is described as 'free association', the mind is relaxed and focused on to only one subject such as breath, it creates new synapses and connections by picking up topics from the unconscious fountain of knowledge that have been collected. The psychologists researched with experiments such as divergent thinking questionnaires and declared that, in the REST mode, while the mind is quiet, meditative and free thinking, the brain generates new creative ideas. 
Thus, the paper aims to ask, what is the effect of spaces to this REST mode and creative process? Can meditative and restorative environments support the REST mode and enhance the creativity during architectural education? Free association REST mode focuses on the principle of free circulating thought, allowing relaxation and free thinking to lead to new connections (creative moments) in the brain. As Andreasen (2006) noted, the source of unconsciousness brings about a creation process as the result of new connections and synapsis during the free-movement thought. Working in this sense; accepting that creativity is a complex process and that it depends on senses, observation, culture, field, stimuli and tests, the paper aims to focus on how spaces affect creative process in case of architectural education, production and creation. If REST mode as relaxation, meditation focus and awareness support the process of creation how does restorative (calming, meditative) spaces and environments affect this process as well?

Kaplan, Kaplan, and Ryan (1998) described a restorative environment as a place to rest and recuperate and they stated that 'natural settings are particularly effective for R\&R' ( $p$ 67). A natural landscape can produce a restorative experience and can renew a person's cognitive powers and they are described as spaces with the following characteristics: 'quiet fascination; wandering in small spaces; separation from distraction; wood, stone, and old; and the view from the window (Kaplan, Kaplan, \& Ryan, 1998). Thus, paper aims to ask; can restorative spaces enhance and stimulate the creative process -described as A-ha moment and REST mode?

As a case study, a questionnaire is prepared and asked to third- and fourth-year students of iTÜ Architecture Faculty, in order to get a data from the results if restorative spaces and meditative moments support their creativity in design process and how does creative process being affected by the environment? As neuroscience declares; our environment has many effects on our behaviours. Thus, for to develop the creative process in architecture education, learning environments should inherit related qualities. The result of the questionnaire is expected to give feedback about architecture education environments and if meditative spaces are affecting the creative process in a positive way. 
Andreasen, N. (2006). The Creative Brain: The Science of Genius, Plume.

Bohm, D. (1998). On Creativity, Routledge.

Csikszentmihalyi, M. (2013). Creativity: Flow and The Psychology of Discovery and Invention. Harper Perennial.

DEBONO, E. (1993). Serious Creativity: Using the Power of Lateral Thinking to Create New Ideas. London: Harper Collins Publishers.

DEMIRBAS, O. \& DEMIRKAN, H. (2000). Privacy dimensions: a case study in the interior architecture design studio. Journal of Environmental Psychology, 20, (1), 53-64.

Freeman, J. (1971). Creativity: A Selective Review of Research, Society for Research into Higher Education Ltd, pp.41.

Guilford, J. P. (1950). Creativity. American Psychologist, 5(9), 444-454.

HASIRCI, Deniz. (2000). The Effects of the Design and Organization of Learning Environments on Creativity: The Case of Two Sixth Grade Art-Rooms. MFA Thesis. Bilkent University. Kaplan, R., Kaplan, S. \& Ryan, R (1998). With people in mind: Design and management of everyday nature. Washington, D.C.: Island Press.

Kaufman, S., Gregoire, C. (2015). Wired to Create: Unravelling the Mysteries of the Creative Mind. TarcherPerigee.

Mallgrave, H.F. (2011). The Architect's Brain: Neuroscience, Creativity, And Architecture. Wiley-Blackwell.

Parnes, J. (1963). Education and Creativity, Teachers College Record, vol64, 1963, pp. 331-339.

Portillo, M. (1996). Uncovering implicit theories of creativity in beginning design students. Journal of Interior Design, 22(2), 16-24.

Potur, A., Barkul, A. (2006). Creative Thinking in Architectural Design Education, 1st International CIB Endorsed METU Postgraduate Conference Built Environment \& Information Technologies, Ankara.

Runco, M. (2014). Creativity: Theories and Themes: Research, Development, and Practice, Academiz Press. 


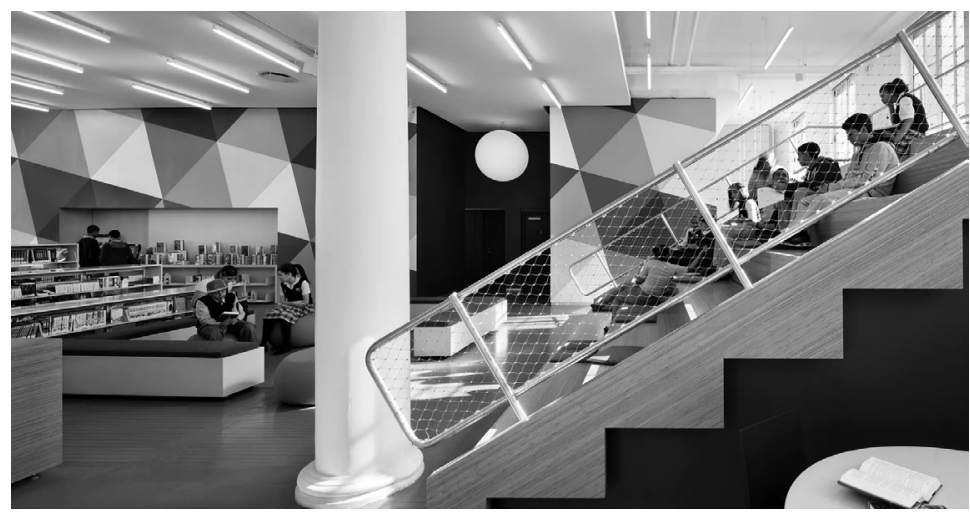

1: Kew Gardens Hills Library, photo by Michael Moran. (https://www.curbed. com/2018/5/24/17389648/library-architecture-teens-public-space)

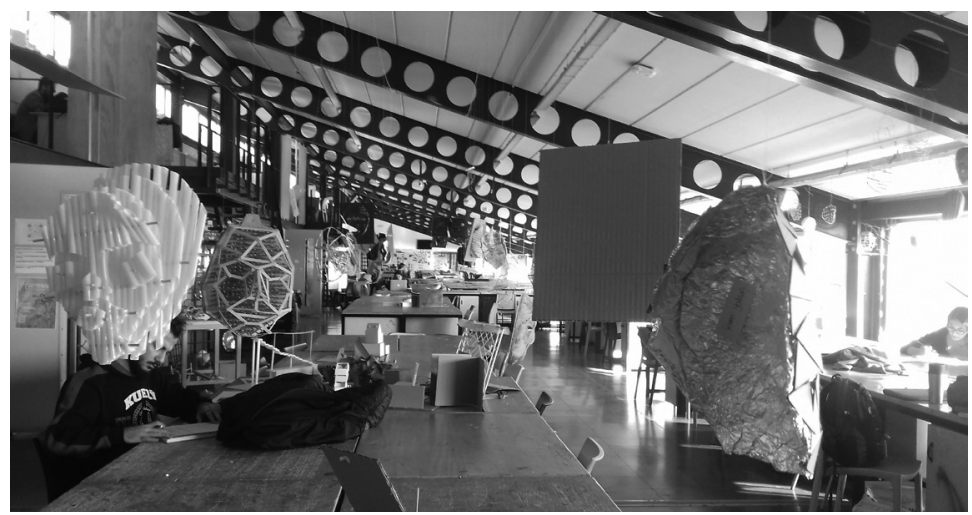

2: Photo from ITU, architecture studios. Photo by the author.

$$
\underset{\text { REST mode }}{\text { Brain is active }} \longrightarrow \begin{aligned}
& \text { Free association } \\
& \text { idea experience }
\end{aligned} \longrightarrow \begin{aligned}
& \text { SEKONDER CORTEX } \\
& \text { Connection in the brain } \\
& \text { ASSOCIATION }
\end{aligned} \quad \begin{aligned}
& \text { Inspiration- } \\
& \text { Production }
\end{aligned}
$$

\section{CREATUVTY PROCESS DUFFERENT CHARACTERISTICS}

\begin{tabular}{|l|}
\hline FIRST PROCESS \\
-PREPARATION \\
-INCUBATION \\
-INTERACTION \\
-DATA COLLECTING \\
-SHARING \\
-RESEARCH \\
\hline
\end{tabular}

ए

COMPLEX, INTERACTIVE, DEPENDING ON ORSERVATION, AND SENSES AND ENVIRONMENTS

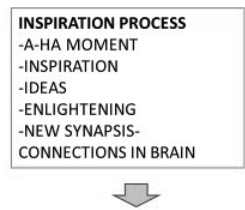

FOR REST MODE, CALM, RESTORATIVE ENVIRONMENTS THAT LEADS TO FREE ASSOCIATION OF THOUGHT.

3: explains the different phases of creativity and their environmental relations. Prepared by the author from the readings and interpretations of Freeman (1971) and Andreasen (2006). 


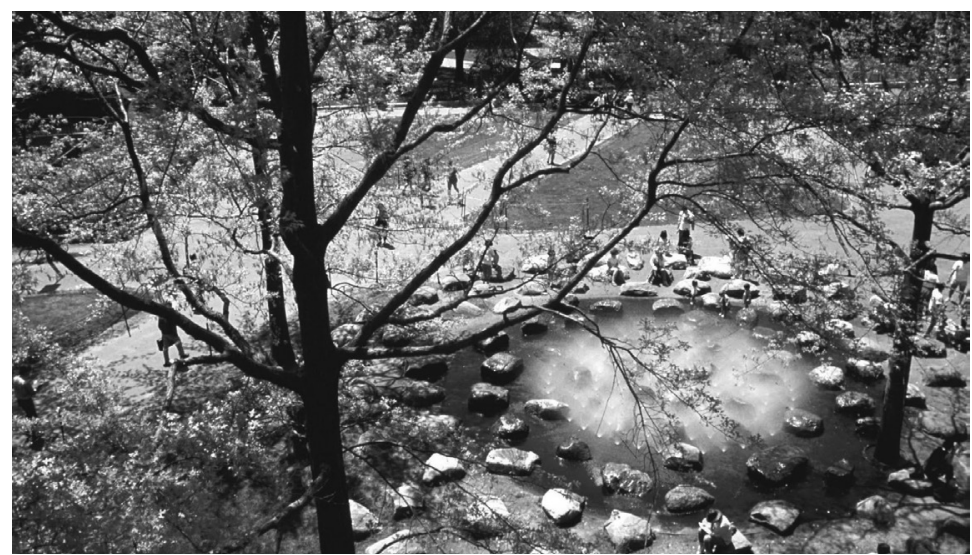

4: Tanner Fountain in Harvard University, photo by Alan Ward. (https://www. asla.org/awards/2008/08winners/312.html)0

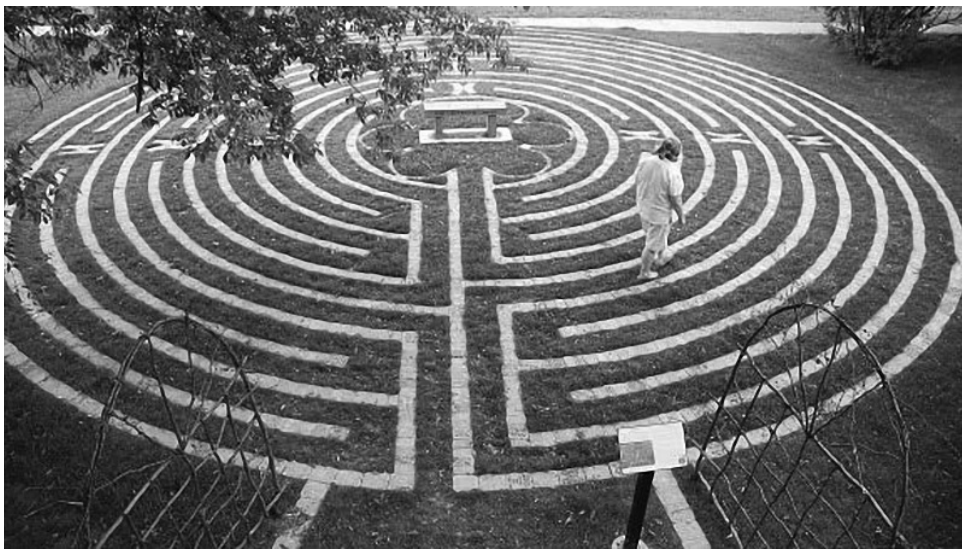

5: Metropolitan State University, Library's Labyrinth Garden. (http://www. bestcounselingschools.org/best-campus-meditation-spaces/)

Image 1 and 2 explain the complex and interactive quality of creative process, and show the interactive environments (that support first two stages of creativity stated by Freeman); for data sharing, preparation, research, data hunting etc. which are all dynamic and complex processes that need suitable environments such as gathering, exhibiting, sharing, experimenting etc.

Image 4 and 5 show restorative environments that can support the REST mode by creating meditative state and supporting the creative process in educational environments. 